Nevena Bulajić

Univerzitet Crne Gore, Filozofski fakultet, Crna Gora doi: 10.19090/zop.2017.26.31-50

UDC: $37.064 .2: 37.04$

Pregledni rad

\title{
RAZMATRANJE MOGUĆNOSTI PRIMENE ,SCAFFOLDING“-A U SAVREMENOM VASPITNO-OBRAZOVNOM PROCESU
}

\begin{abstract}
Apstrakt. „Scaffolding“" je savremeni pedagoški pristup koji su uveli Wood i saradnici (1976) pokušavajući da, polazeći od pedagoških pogleda Lava Semjonoviča Vigotskog, utvrde najvažnije komponente podučavanja. Promene u novom veku utiču na demografski profil ranog detinjstva koji se u učionici brzo menja, te je neophodno i naše teorije, ideje i vaspitno-obrazovnu praksu menjati. Jedna od najvećih debata u oblasti ranog detinjstva jeste definisati ulogu usmerenog nastavnika u pristupu koji dete stavlja u centar vaspitnoobrazovnog procesa. Razmatranjem suštine „scaffolding“-a, zasnovanog na interakciji, kokonstrukciji, intersubjektivnosti i značaju uloge odraslog u maksimalizaciji detetovih potencijala i razvoju metakognicije u različitim domenima razvoja (kognitivni, socijalni, emocionalni, fizički i domen jezika), ukazujemo na njegovu pedagošku vrednost i valentnost. Brojne protivrečnosti postmodernog poimanja detinjstva ukazuju na potrebu za pedagoškim pristupom zasnovanim na širokom polju intersubjektivnosti, koji pretpostavlja upravo primenu "scaffolding"-a. Analizom raspoložive naučno-istraživačke građe, upotpunjujemo u literaturi najčešće prisutno shvatanje "scaffolding"-a, kao procesa u kojem se detetu u podržavajućem okruženju obezbeđuju izazovni zadaci i aktivnosti kojima se podstiče njegova sposobnost samostalonog rešavanja problema. Povodom toga, otvaramo pitanje o
\end{abstract}

\footnotetext{
*Bulajić Nevena, nevenabulajic@gmail.com

${ }^{1}$ Termin ,scaffolding“ su prvi put uveli sledbenici Vigotskog, Wood, Bruner i Ross (Berk, Winsler, 1995: 20) razvijajući njegovu teoriju. Ovaj termin našao se posebno pogodnim za slikoviti opis procesa "podupiranja" učenja i razvoja u okviru zone narednog razvoja, o kojem je govorio Vigotski sa stanovišta saradnje deteta sa odraslom osobom (vaspitač, učitelj, nastavnik, roditelj, sposobniji vršnjak). U doslovnom prevodu na srpskom jeziku označava „skele“ i ova metafora konotira veoma specifičan sistem socijalne podrške za detetove napore, koji je brižljivo podešen prema njihovim potrebama (Berk, Winsler 1997: 20). U literaturi na našem govornom području srećemo prevod: „vođena participacija“ i „aproprijacija“ (Slunjski 2012: 108-113). Međutim, zbog neadekvatnog jezičkog prevoda, koji ne obuhvata sve elemente ovog pristupa, koje ćemo dalje razmatrati, zadržavamo termin "scaffolding" u tekstu koji najviše odgovara kontekstu o kojem je reč.
} 
mogućnosti njegove integracije u našu pedagošku praksu i adekvatnog prevoda termina na našem jeziku u cilju njegovog lakšeg prihvatanja, poimanja i upotrebe u pedagoškoj teoriji i praksi.

Ključne reči: "scaffolding"; interakcija; učenik; nastavnik; podučavanje.

\section{UVOD}

Prema sociokulturnoj teoriji Lava S. Vigotskog, novi kapaciteti u detetu razvili su se tokom njegove saradnje sa odraslima ili vršnjacima višeg razvojnog nivoa, a potom se internalizovali u njegov psihički svet (Blanton, Menendez, Moorman, Pacifici, 2013). Vigotski (1930-31) je u svom radu postavio hipotezu o poreklu razvoja viših psihičkih funkcija koja glasi: "Svaka psihička funkcija je bila spoljašnja, jer je, pre no što je postala unutrašnja, čisto psihička funkcija, bila socijalna; ona je najpre bila socijalni odnos između dvoje ljudi” (Vigotski, 1996: 305). Njegove ideje se zasnivaju na dva osnovna načela (Blanton et al., 2013):

1. Ljudska svest razvija se putem kulturno posredovane ljudske aktivnosti s obzirom da uključivanje instrumentalnih i psiholoških alata u ljudskoj aktivnosti ima izrazit uticaj na razvoj psiho-fizičkih funkcija;

2. Prvi psihološki procesi su društveni procesi koji se nalaze na socijalnom planu, a kasnije se internalizuju u pojedincu kao psihološki procesi koji ga uče da reguliše svoje aktivnosti i učešće drugih u društvenim aktivnostima.

Kako se demografski profil ranog detinjstva u učionici brzo menja, tako je neophodno i da se naše teorije, ideje i obrazovna praksa menjaju (Winsler, 2010), te da se deca tokom vaspitanja i obrazovanja, posebno institucijskog, pripremaju za stalnu promenu, snalaženje s nesigurnošću, nepredvidivošću i višedimenzionalnošću savremenog života (Slunjski, 2009). Marjanovićeva instituciju shvata kao ,zajedničko mesto življenja deteta i odraslih“, iz čega proizilaze dva bitna pitanja: pitanje uzajamnih položaja dece i odraslih i pitanje kvaliteta interakcije koja se u ustanovi uspostavlja 
(Marjanović, 2013). Prema Vigotskom, nastavnici ${ }^{2}$ su ključni posrednici interiorizacije kulturnih vrednosti, zbog čega ova uloga postaje mnogo značajnija u oblasti obrazovanja učenika kao subjekta obrazovanja, ili kao "sirovog materijala" u rukama nastavnika (Yudina, 2010). Vigotski obrazovanje posmatra kao proces vođenog razvoja. Kroz saradnju sa nastavnicima, učenik aktivno konstruiše nove kognitivne sposobnosti (Berk \& Winsler, 1995). Freire P. (1972) smatra da nastavnici treba da praktikuju ko-intencionalnost u učionici, a kritikuje "bankovni" sistem obrazovanja zasnovan na transmisiji znanja u kojem nastavnik daje znanje i "depozit" činjenica učenicima i "stavlja" ih u njihovu "bankovnu" memoriju (Scrimsher \& Tudge, 2010).

Nakon rada Vigotskog (1976), stavljen je veći naglasak na ulogu nastavnika, međutim Johnson, Christie, i Wardle (2005) navode - na temelju istraživanja - da se nastavnici više bave upravljanjem i praćenjem a ne podržavanjem i razvojem ko-konstrukcije ${ }^{3}$ (Bennett, Rogers, Wood, 1997; Kontos, 1999; Pramling Samuelsson, Johansson 2009; Rogers, Evans 2008, prema: Crowley, Miles, Mclnnes, Howard, 2013). Novi zahtevi koje nameće nova praksa, tj. potreba korenitog revidiranja dugogodišnjih uverenja, mogu izazivati različite "turbulencije" u svesti nastavnika (Slunjski, 2009: 107). Autonomija i nastavnika i učenika mora biti shvaćena u „terminima odnosa“ (Wyness, 2013: 433). „Veza između participacije i autonomije protkana je u pojačanom odnosu međuzavisnosti nastavnika i učenika“ (Wyness, 2013: 433). Više nego ikada ranije, sada nam je neophodna sociokulturna teorija Vigotskog, koja nam nudi niz konceptualnih alata za razumevanje i ispitivanje opštosti i varijacija u okviru kulturne i jezičke prakse - kako bi nam pomogla da razumemo, zastupamo i pedagoški delujemo na sve veće

\footnotetext{
2 U celokupnom radu terminom "nastavnik" podrazumevamo individuu koja se bavi vaspitno-obrazovnim radom na predškolskom i osnovnoškolskom obrazovnom nivou kako bismo izbegli pojedinačno nabrajanje svih profesija koje dalje vezujemo za primenu "scaffolding"-a (vaspitač, učitelj, nastvnik).

3 „Ko-konstrukcija“, kao ključni termin u savremenom poimanju učenja, naglašava da „,nastavnik i dete zajedno studiraju značenja pre nego li prosto usvajaju činjenice“, i na taj način „osmišljavaju svet... u interakciji jednih sa drugima“ (Jordan, 2009: 33).
} 
etničke, kulturne, jezičke raznovrsnosti današnjeg ranog detinjstva u učionici (Winsler, 2010).

Cilj ovog rada je da se putem sistematičnog upoznavanja pedagoških ideja Vigotskog, koje se modifikuju u "scaffolding"-u, ukaže na značaj njegove primene u savremenom vaspitno-obrazovnom procesu, zasnovanom na interakciji, ko-kostrukciji, intersubjektivnosti, kao i na značaj uloge nastavnika i sposobnijih vršnjaka u postizanju vaspitno-obrazovnih ciljeva. Temeljnim objašnjenjem "scaffolding"-a i njegovog uticaja na celokupan razvoj učenika, otkrivamo pokazatelje i smernice koje bi trebalo da se na kvalitetan način integrišu u pedagošku praksu na našem prostoru.

\section{POJAM I SUŠTINA "SCAFFOLDING”-A}

Jedna od najvećih debata u oblasti ranog detinjstva neko vreme bila je: definisati ulogu nastavnika za optimizaciju i zdrav razvoj učenika u učionici duž kontinuuma "dete u centru" i "usmereni nastavnik" (Winsler, 2010). Uz to, kako navodi Marjanovićeva (1987), čovek danas živi u društvu kojem je "modus vivendi promena", zbog čega mu je potreban jedan potpuno drugačiji repertoar sposobnosti, te Wyness predlaže „relacioni“ pristup participaciji, koji podrazumeva pojedinačno i ulogu dece i ulogu odraslih (Slunjski, 2009: 110; Wyness, 2013: 435). U tom smislu, direktno poučavanje mora se zameniti saradničkim učenjem i samoučenjem dece i aktivnostima kooperacije uz visok stepen dečje participacije (Miljak, 2009).

Navešćemo specifična određenja "scaffolding"-a sa aspekta različitih autora koji su, polazeći od pedagoških ideja Vigotskog, razmatrali njegovu fundamentalnost i dali doprinos razumevanju pojedinih ključnih karakteristika ovog koncepta.

"Scaffolding"-om se opisuje određena vrsta pomoći nastavnika ili sposobnijeg vršnjaka koja se odlikuje zajedničkim učešćem, pregovaranjem i angažovanjem i maksimalnim učešćem učenika u aktivnostima, pri čemu se sprovodi pažljiva modulacija vrste pomoći nastavnika i povlačenje pod uslovom da se učenik zadrži u zoni narednog razvoja ili "ZDP" (Winsler, 2010). Wood (1976) je "scaffolding" predstavio kao proces "snimanja" raznovrsnih aspekata podrške nastavnika u naporima učenika pri rešavanju 
određenog zadatka, na nivou na kojem je radno sposobno (Jordan, 2004). Greenfield, Giffin i Cole (1984) ovaj koncept posmatraju kao "region osetljivosti na instrukcije", koji je usko povezan sa "ZDP", i ističu da "scaffolding" ne pojednostavljuje zadatke na korake, već podrazumeva pružanje postepene podrške putem kvantitativne i kvalitativne pomoći (Evans, Moretti, Fox, 2010). Rogoffova "scaffolding" interpretira kao koncept vođenog učešća ne samo interakcije "face to face"(licem u lice) već i „side by side“(uporedo), što se odnosi na sisteme angažovanja između učesnika u kojima oni komuniciraju i koordiniraju svoje napore dok učestvuju u kulturno-vrednosnim aktivnostima (Rogoff, 1990).

Ideja "scaffolding"-a podrazumeva inovativan način učenja u državnim školama, gde aktivnosti učenja planiraju učenici i nastavnici - kroz saradnju. Nastavnici ohrabruju rukovodstvo učenika i uče iz iskustva svog angažmana u aktivnostima sa učenicima čime se eleminiše dihotomija učenja bazirana na kontroli (Rogoff, 2001). Postoji protivrečnost, jer sa jedne strane nastavnici žele da neguju, vode i nauče učenike, pri čemu im "scaffolding" služi da pomognu učenicima da ostvare svoj najveći potencijal, dajući zadatke u skladu sa kognitivnim nivoom učenika, ali i zadatke koji su neznatno iznad stečenih mentalnih operacija kako bi aktivirali procese koji se pojavljuju u rudimentarnom obliku. Sa druge strane, nastavnici žele da podstaknu autonomiju učenika, da ih puste da sami reše svoje probleme i omoguće im slobodu izbora (Berk \& Winsler, 1995; Winsler, 2010).

U tom kontekstu, naša perspektiva je fokusirana na jedno savremeno pedagoško delovanje u vaspitno-obrazovnom procesu, koje opisuje i objašnjava upravo "scaffolding" pristup. Primena "scaffolding"-a ne ograničava se uzrastom, pa samim tim ni obrazovnim nivoom, kao ni kontekstom u kojem se realizuje, što dovodi do zaključka da bi validno odgovorio na različite vaspitno-obrazovne, društveno-kulturne, tehničkotehnološke i ekonomske zahteve i promene novog veka. Ipak, u radu smo fokusirani na mogućnost njegove primene posebno u predškolskim i osnovnoškolskim instituacijama s obzirom na značaj njegovog uticaja na različite domene razvoja deteta. 


\section{ANALIZA I RAZMATRANJE STRUKTURNIH ELEMENATA "SCAFFOLDING"-A}

Nastavnici širokog spektra prakse ukazuju posebno poštovanje prema "scaffolding"-u koji objedinjuje procese ko-konstrukcije i učenja u detinjstvu, u kojem je uloga i zadatak nastavnika pružanje mogućnosti za učenje i učenje zajedno sa učenicima (Jordan, 2004; Rogoff, 2001).

U novijoj literaturi ranog detinjstva, na primer Berk i Winsler (1995), razvijeno je više generičkih elemenata efikasnog "scaffoldig”-a zasnivajući se na istraživanjima koja su pokazala njihovu delotvornu funkciju (Berk \& Winsler, 1995; Jordan, 2004): 1. Zajedničko rešavanje problema; 2. intersubjektivnost; 3. toplina i odgovornost; 4. podržavanje deteta u zoni narednog razvoja; 5. promovisanje samoregulacije.

U cilju potpunijeg razumevanja "scaffolding"-a i njegovog uticaja na različite domene razvoja učenika, osvrnućemo se na detaljniju analizu i razmatranje njegovih međusobno povezanih strukturnih elemenata.

\section{Zajedničko rešavanje problema}

Prva komponenta "scaffolding"-a jeste angažovanje učenika u zanimljivoj i kulturno značajnoj aktivnosti koja naglašava aktivnu prirodu razmišljanja, preferira pokušaje individua da regulišu tok života i rade oko problema kako bi zajednički pokušali da postignu određeni cilj (Berk \& Winsler, 1995; Rogoff, 2001).

Rešavanje problema ispituje integrisane mentalne procese koji se u nekim pristupima tretiraju odvojeno: sećanje, planiranje i kategorizaciju kao aspekte verovatnoće rešavanja problema. To obuhvata kognitivne procese i veštine u korišćenju tehnologije (pisanje, obračunavanje) i probleme koji uključuju smisaono instumentalno korišćenje drugih ljudi da se postignu ciljevi (Rogoff, 2001). U procesu zajedničkog rešavaja problema, učenik i nastavnik vide stvari na nov način, stiču nove veštine i uče kako da kompetentnije rade zajedno (Scrimsher \& Tudge, 2010). Učenik i nastavnik, kao subjekti u ovom procesu, istovremeno su jedan drugom i učenik i nastavnik (Freire, 1996). 
Postoje specifične strategije koje nastavik ili sposobniji vršnjak može koristiti pomažući učenicima da koriste i primenjuju psihološke alate; to su: modeliranje, demonstriranje, ispitivanje, pomaganje učenicima u donošenju i izvršavanju planova (Helm, 2015). U ovom procesu nastavnik ili vršnjak višeg razvojnog nivoa postepeno učenika oslobađaju svoje kontrole, kada sposobnost učenika da prihvati odgovornost u završavanju zadatka dostigne adekvatan nivo (Jordan, 2004). Manje su mogućnosti za to ukoliko se nastavni proces bazira samo na izradi radnih listova i propisanih aktivnosti učenja (Helm, 2015).

U eksperimentu koji je Vigotski organizovao, pokazalo se da dete $\mathrm{u}$ problemskoj situaciji u saradnji objedinjuje dva prilaza u jednu sinkretučku celinu. U trenutku kada odrasla osoba proceni da kompetencija deteta raste te se distancira, dete predhodno socijalno organizovanu funkciju premešta na "egocentričan" govor (Vigotski, 1977; 1996), koji jača vlastito razumevanje misli i aktivnosti (Pijaže, 1983) i koji, osim ekspresivne funkcije i funkcije pražnjenja, vrlo lako postaje mišljenje u pravom smislu reči preuzimajući funkciju planiraja operacije i rešavanja problema (Vigotski, 1977; 1996). Bruner smatra da, ako neko može da koristi govor da bi otkrio značenje draži, time se osobađa sveta privida, a njegovo saznanje stiče stabilnost i elastičnost u slučaju da jezički nazivi nude pogodan način za otkrivanje značenja važnih informacija (Tarner, 1979). Dokazano je da se jezik efikasnije razvija u aktivnostima zajedničkog rešavanja problema i korišćenjem otvorenih tehnika ispitivanja koje podstiču razmišljanje i međusobnu razmenu mišljenja među učenicima (Crowley et al, 2013). Vigotski smatra da mišljenje nije ograničeno samo individualnim umom, već je u nerazdvojivoj vezi sa umovima drugih i smatra da iskustvo koje dete stiče u interakciji sa okruženjem oblikuje puteve razvoja njegovog mišljenja i tumačenja stvarnosti (Berk \& Winsler, 1995).

\section{Intersubjektivnost}

Savremena perspektiva o detetu, kako navodi Malaguzzi, ne posmatra dete kao izolovano i egocentrično, koje je samo u akciji sa predmetima, ne naglašava samo kognitivne aspekte niti omalovažava ono što nije logično 
(Anning, 2004), već smatra kao da je dete bogato potencijalom, jako, moćno, kompetentno i povrh svega povezano sa odraslima i drugom decom (Fleer \& Richardson, 2004).

Komponentu “intersubjektivnosti” uveli su Newson i Newson (1975); ona daje specifičan "kvalitet" učenju i označava nešto što je zajedničko između subjekata ili za sve subjekte, zavisi u kojem kontekstu se koristi (Berk \& Winsler, 1995; Miljak, 2009). Miljak ističe da se učenje ne dešava primarno i u potpunosti „u glavama“ učenika, već je pre svega locirano u "prostoru” zajedničke prakse nastavnika i učenika ili među učenicima, označavenom kao polje intersubjektivnosti, u kojem se događa učenje (Miljak 2009: 25). Intersubjektivnost, fundament ko-konstrukcije, odnosi se na proces u kojem dva učesnika prilaze određenom zadatku sa različitim razumevanjem pri čijem se rešavanju dolazi do njegovog zajedničkog razumevanja (Berk \& Winsler, 1995), a zajedničko razumevanje je bazirano na zajedničkom fokusu pažnje i zajedničkim pretpostavkama koje daju osnovu za komunikaciju (Rogoff, 1990: 71).

U ovom kontekstu, nužno je podsetiti se Habermasove konceptualizacije komunikacione akcije, koja se odvija onda kada „učesnici koordiniraju svoje akcije ne prema egocentričnim kalkulacijama uspeha, već u nastojanju da dosegnu razumevanje“ (Habermas, 1987: 285, 286), jer je dostizanje razumevanja „telos inherentan ljudskom govoru“ (Habermas, 1996: 287). Nastavnik treba da prilagodi objašnjenja novou učeničkog razumevanja, te ko-konstrukcija samim tim zavisi od nivoa i količine zajedničkog razumevanja, što zavisi od metaforičke udaljenosti učesnika i raspodele moći između njih (Jordan, 2004). Postizanje razumevanja odvija se u prostoru ,intersubjektivne uzajamnosti recipročnog razumevanja, deljenja znanja, uzajamnog poverenja i međusobnog sporazuma“ (Habermas, 1979:3), koji kreira optimalne uslove, što pospešuje komunikaciju i ovladavanje govorom (Jordan, 2004); ovladavanje govorom dovodi do reorganizacije celokupne psihičke strukture (Vigotski, 1996), te ovaj proces sam po sebi uključuje kognitivne, socijalne i emocionalne razmene (Rogoff, 1990). Kognitivni "scaffolding", usko je povezan sa verbalnim koji zahteva strategije u kojima nastavnik podržava narativni razvoj učenika kroz dijaloge (Pesco \& Gagne, 2015). Govor koji omogućava opštenje i razmenu sa 
drugima neophodan je za razradu operacionih struktura, ali pre u obliku kooperacije nego nametnutog prenošenja (Pijaže, 1983). Vigotski veruje da je govor kao "alat uma" zapravo izdanak primarne komunikativne funkcije jezika i da ima važne implikacije za kvalitet mentalnih procesa (Berk \& Winsler, 1995).

Takvi trenuci zajedničke aktivnosti, komunikacije i podrške obuhvataju: „scaffolding“ i sukonstrukciju razumevanja i znanja, obuku, vođenu participaciju i aproprijaciju, a odnose se i na rutinske prećutne aktivnosti i angažmane učenika i nastavnika. One mogu ali i ne moraju imati funkciju eksplicitne lekcije za decu, ali predstavljaju dobar materijal za razvoj (Rogoff, 1990; Slunjski, 2012: 108-113). Jasno je da je u ovoj vrsti interakcije kod partnera prisutna asimetrija u odnosima. Ona je posebno karakteristična upravo za osnovnu pedagošku dijadu nastavnik-dete, a ,veća razlika u raspodeli moći odraslih i dece za sobom povlači i manje polje intersubjektivnosti..." (Slunjski 2012: 108). Minimalno je u aktivnostima kojima upravlja isključivo nastavnik ili učenik a neuporedivo veće $u$ aktivnostima u kojima su učenik i nastavnik jednaki partneri u komunkaciji i učenju (Jordan, 2004).

Emocionalni aspekt "scaffolding"-a-toplina i odgovornost

Angažovanje učenika prilikom rešavanja nekog zadatka, kao i njegova spremnost na korekcije, maksimalizuje se ako se saradnja sa nastavnikom zasniva na prijatnoj povratnoj informaciji (Berk \& Winsler, 1995). Marjanovićeva upozorava na izraženu emocionalnost deteta/učenika te potrebu da mu se pomogne da stekne uvid u značenje i vrednost svojih emocija, da stekne sposobnost empatije, kao i motivacionu vrednost emocija (Marjanović, 2013: 85).

Nastavnik treba da opservira aktivnost učenika, pažljivo učestvuje u njegovom sledećem potezu i bude angažovan u onoj meri koja je dovoljna da obezbedi podršku na intelektualnom i emocionalnom planu (Berk \& Winsler, 1995). Liper smatra da emocije imaju funkciju da organizuju i motivišu određeno ponašanje i da u svakom ponašanju postoji izvestan stepen emocija koje usmeravaju i omogućavaju izbor uzmeđu alternativa ili rešenja problema 
(Redford \& Kirbi, 1979). Zadovoljstvo koje učenik dobija u samom procesu aktivnosti neophodan je biološki faktor za izgradnju ma kakve navike za koju je potrebno da sama aktivnost - a ne njeni rezultati - nalazi u sebi sve vreme podržavajući stimulans. Zadovoljstvo, navodi Bühler K, migrira, luta, menja svoje mesto u sistemu psihičkih funkcija i takvim svojstvima odlikuju se procesi stvaralačke igre, odgonetanja nekog zadatka i rešavanja određenog problema (Vigotski, 1996). P. T. Jang navodi da emocije pokreću na akciju, pobuđuju organizam na delatnost i doprinose održavanju ponašanja dok se ne postigne određeni cilj (Redford \& Kirbi, 1979). Aktivnost koja se preobražava u intelektualnu, čija se suština sastoji u onome što Bühler K. naziva reakcijom odgonetanja (aha reakcijom), karakteriše se organizacijom emocionalnog života $\mathrm{u}$ trenutku kada individua izražava emocionalni doživljaj (Vigotski, 1996). U zavisnosti od toga kako se nastavnik emotivno postavi prema učeniku, njegova samokritičnost će varirati pozitivnom ili negativnom tendencijom (Redford \& Kirbi, 1979).

Pijaže (1983) preoperacioni stadijum (2-7 god), opisuje kao međusobno preplitanje raznovrsnih osećanja koja formiraju nova. Osećaj poštovanja prema odraslima omogućava detetu da zahteve shvati kao obavezne što kod njega razvija osećaj dužnosti. Stadijum konkretnih operacija (7-11 god) obeležavaju obostrano poštovanje, težnja pojedinca da usklađuje svoje odnose sa drugima i da ih ne remeti lažima i slično, što kod deteta ovog uzrasta razvija osećanje pravednosti (Pijaže i Inhelder, 1983).

Dakle, interaktivni odnos u "scaffolding"-u, baziran na emocionalnoj podršci i razmeni učenika i nastavnika, obrazuje atmosferu koja ustrojava intelektualni, emocionalni i socijalni razvoj.

\section{Podržavanje deteta u zoni narednog razvoja}

Vigotski navodi da ne treba meriti ono što dete može samostalno da uradi ili što zna, već šta može da uradi uz pomoć druge osobe i koliki je njegov potencijal za učenje. On je kritikovao tradicionalne testove intelektualnog funkcionisanja koje su konstruisali psiholozi (Alfred Bine i dr) smatrajući ih krajnje limitiranim jer ocenjuju "statičke" i "okamenjenje" 
sposobnosti ne uzimajući u obzir dinamiku i menjanje kvaliteta ljudske kognicije (Berk \& Winsler, 1995).

Konstatacijom različitih simptoma prilikom određivanja realnog nivoa razvoja deteta, dobijamo samo opštu sliku o formiranim procesima i funkcijama, ali to nije dovoljno da otkrijemo fundamentalni nivo razvoja. Prema zakonu razvoja, kada se određene strukture i funkcije formiraju, dolazi do reorganizacije struktura i javljaju se novi procesi koji su $u$ fazi sa formiranjem; njihovo određivanje rešava se nalaženjem zone narednog razvoja ili "ZDP”(zone of proximal development) (Vigotski, 1996). Vigotski je definisao "ZPD" kao prostor između stvarnog nivoa razvoja individue, koji je određen nezavisnim rešavanjem problema, i nivoa potencijalnog razvoja, definisanog rešavanjem problema pod vođstvom odraslog ili $\mathrm{u}$ saradnji sa sposobnijim vršnjacima (Berk \& Winsler, 1995: 26). Rogoff i Gardener (1984) smatraju da je "ZDP" faza u razvoju kognitivnih veština koje dete samo delimično savlada ali ih može uspešno usvojiti i internalizovati uz pomoć i nadzor odrasle osobe (Evans et al., 2010). Cole (1985) ukazuje na to da se u "ZDP" kultura i spoznaja međusobno kreiraju (Rogoff, 1990).

Predlažemo da suštinska odlika nastave/učenja bude stvaranje zone narednog razvoja; to jest, da nastava/učenje budi različite razvojne procese koji se mogu aktivirati samo kada je dete u interakciji sa ljudima iz svog okruženja i u kolaboraciji sa svojim vršnjacima (Vygotsky, 1935/1978, str. 90, prema: Scrimsher \& Tudge, 2010).

Ključni izazov edukatora u "scaffolding"-u jeste definisanje granice "ZDP" podešavanjem podrške u procesu učenja - do naredne tačke od one koja reflektuje trenutnu nezavisnu sposobnost učenika. Svaka vrsta pomoći koja se širi iznad ograničenja zone, biće nedelotvorna i može potencijalno naneti štetu samopouzdanju učenika. Proces podešavanja podrške u zoni može se postići na dva načina (Berk \& Winsler, 1995) i to su:

1. konstruisanje zadataka $i$ okruženja tako da zahtevi u svakom trenutku budu na odgovarajućem intelektualnom izazovnom nivou. Može se sprovesti istovremeno prećutno i eksplicitno. Nastavnik oblikuje i selektuje aktivnost u skladu sa odgovarajućim trenutkom u kojem ona treba da se odvija i postavlja pravila u okviru kojih učenik 
može funkcionisati. Postoje različiti načini kako bi se olakšali zahtevniji zadaci; na primer, Bruner govori o verbalnom razlaganju zadatka na prostije komponente tako da dete može samo da uvidi koja je stavka koja sledi njegovom rešenju;

2. podešavanje intervencije odraslih trenutnim potrebama $i$ aktivnostima deteta. - Podrazumeva pružanje pomoći kada je to potrebno, kao i smanjivanje učešća nastavnika u realizaciji zadatka kada kompetentnost učenika raste i kada ono već samo uspostavlja određene veze i odnose među elementima kako bi samostalno došlo do cilja. Ovo je ujedno i najšešća interpretacija "scaffolding"-a, kada se odgovorom i kontigentom interakcije u podržavajućem okruženju, obezbeđuju detetu odgovarajuće izazovne aktivnosti i zadaci u kojima se podstiče njegova kompetencija samostalnog rě̌avanja datog problema.

Sigel i njegovi saradnici definisali su tri nivoa pomoći nastavnika u kontekstu "scaffoldng"-a (Berk \& Winsler, 1995); primenjuju se u zavisnosti od stepena razvoja, nivoa nezavisnosti i unutrašnje motivacije učenika (Kuyk, 2011) i to su:

1. nizak nivo podrške - preferira se visok nivo motivacije i visok stepen nezavisnosti i razvoja učenika. Uloga nastavnika je da obezbedi situacije u kojima učenik može da reši probleme visokog nivoa, da ga podrži u pronalaženju rešenja i ne dozvoli učeniku da se zadovolji najednostavnijim rešenjem;

2. srednji nivo podrške - prilagođava se srednjem nivou razmišljanja tj. nižem nivou nezavisnosti, razvoja i motivacije učenika. Na ovom nivou učeniku je u većini vremena potrebna strateška pomoć (kako da realizuje aktivnost), ali i podrška u samom sadržaju;

3. podrška na visokom nivou - za učenika koji ima nizak nivo razmišljanja, podrazumeva više podrške, vreme i sistematično učenje, u malim koracima u kojima mu uvek treba dozvoliti da donese sopstvene odluke i kreira svoje rešenje. Ponekad i nije važno naći pravo rešenje jer je napor da se pronađe rešenje od ključnog značaja. S obzirom da u okviru "ZDP” uvek postoji zajednička aktivnost dvoje ljudi, odnosno nastavnika i učenika, kada govorimo o vaspitno-obrazovnom 
procesu, postavljaju se određena pitanja realizacije tih aktivnosti. Ko bira te odgovarajuće aktivnosti i šta je opseg ovog izbora? Ko postavlja zadatke koji će osigurati efektivno razvijanje "ZDP”? Koja vrsta nastavnikove pomoći je najprikladnija za kreiranje "ZDP" u odnosu na učenika, sa jedne strane, i u odnosu na nastavnikove obrazovne zadatke, sa druge strane? (Yudina, 2010).

\section{Promovisanje samoregulacije u "scaffolding"-u}

Sledeći važan cilj "scaffolding”-a je podsticanje samoregulacije kod učenika i regulisanje zajedničke aktivnosti u najvećoj mogućoj meri. Prema postojećim istraživačkim dokazima, tri glavne oblasti imaju veoma značajan uticaj na pojavu samoregulišućih kognitivnih aktivnosti (Bingham, Grau, Pino Pasternak, Sangster, Whitebread, 2007):

1. metakognitivno znanje: individualno znanje o personalnim zadacima i strategije varijabli koje utiču na njihov kognitivni učinak;

2. metakognitivna regulacija: kognitivni procesi koji se odvijaju u toku tekuće aktivnosti, uključuju: planiranje, monitoring, kontrolu i evaluaciju;

3. emoconalna $i$ motivaciona regulacija: učenik prati i kontroliše emocije i motivaciono stanje tokom zadatka za učenje.

Podrška nastavnika je mnogo moćnija od same samoegulacije, jer uz podršku učenik uči u svakom ciklusu rasta, na višem nivou. U "scaffolding”u nastavnik postavlja relavantna pitanja i daje odgovarajuće signale i ,odriče“ se kontrole i pomoći onog trenutka kada učenik počne da izvršava aktivnost nezavisno od nje. Na taj način učenik ostaje $\mathrm{u}$ onome što se naziva zona izvršnog funkcionisanja. Istovremeno, obezbeđuje se dostizanje optimalnog nivoa razvoja (Berk \& Winsler, 1995; Kuyk, 2011).

Deca žele da ispune standarde odraslih i ona su suštinski motivisana da u takvom okruženju nauče veštine odraslih (Kuyk, 2011). Prema Leontievu, veštine čitanja i brojanja dete uči u početku obavljanjem spoljne akcije uz podršku međuljudskog konteksta. Čitanjem naglas drugoj osobi, praćenjem teksta dok druga osoba čita ili glasnim računanjem sa drugim koristeći prste, dete internalizuje i formira nove sposobnosti i proizvodi ih $\mathrm{u}$ cilju njihovog dostizanja sposobnostima odraslih (Duncan \& Tarulli, 2010). 
Davanje odgovornosti igra važnu ulogu u učenju individue i ovladavanju vlastitog ponašanja. Tom prilikom učenici aktivno prilagođavaju svoje uključivanje i preuzimanje nivoa odgovornosti u zajedničkoj aktivnosti i sami organizuju i usklađuju učešće nastavnika sa svojim interesima (Berk \& Winsler, 1995; Rogoff, 1990). Kad nastavnik govori učeniku šta treba da uradi, učenje i samorgeulacija se reducira; nasuprot tome, postavljanjem pitanja putem kojih će učenik samostalno doći do rešenja - ovi procesi se maksimalizuju (Berk \& Winsler, 1995).

Vigotski tvrdi da je upotreba dečjih verbalnih alata za regulisanje ponašanja drugih značajan faktor u razvoju samoregulacije, jer na taj način dovodi do višeg oblika ponašanja, koji se reflektuje činom usvajanja uloge organizatora vlastitih namera i delovanja (Vigotski, 1996). Priroda zajedničke aktivnosti deteta i odraslog utiče na kvalitet njihove verbalne interakcije, što, zauzvrat, oblikuje njihovo mišljenje (Tulviste, 1991, prema: Berk \& Winsler 1995: 115), ali služi i kao sredstvo autostimulacije. Vigotski je nizom istraživanja utvrdio da dečja sociodrama, ima značajnu ulogu u razvoju samoregulacije (Bingham et al, 2007).

Pijaže (1983) navodi da samoregulacija predstavlja jednu od najuniverzalnijih odlika života i najopštiji mehanizam organskih i saznajnih reagovanja. Autoregulišuće funkcionisanje, koje se neprekidno odvija po stadijumima razvoja, sintezom raznovrsnih oblika regulacije i izvesnim podudarnim funkcionisanjima, čini prethodnicu onoga što se može posmatrati na planu ponašanja (Pijaže, 1983).

Zimmerman i Schunk (2001) su u svom istraživanju primetili da tokom epizode prave saradnje kognitivni procesi regulacije variraju izmedju tri nivoa (Bingham et al, 2007): 1. samoregulaija - temelji se na tradicionalanom konceptu koji se odnosi na praćenje i kontrolu vlastitog učinka (intrapersonalna regulacija); 2. regulacija drugog - odnosi se na situaciju u kojoj je jedan partner dominantan i daje instrukcije drugom; 3 . deljena regulacija (zajednička regulativa) - definiše se kao "egalitaran, komplementarni nadzor i regulacija nad zadatkom".

Dve karakteristike razlikuju interpersonalni od intrapersonalnog nivoa metakognicije (Bingham et al., 2007): 1. rad u saradnji omogućava smanjenje opterećenja kognitivne obrade; 2 . učesnici moraju da $\mathrm{u}$ isto vreme prate $\mathrm{i}$ 
regulišu recipročno korišćenje zajedničkog predstavljanja zadatka, što ih obavezuje da međusobno eksternalizuju i artikulišu svoje ideje i koncepcije.

\section{ZAKLJUČAK}

Polazeći od opšte slike post-tradicionalnog društva ili kasne modernosti, uviđamo nesklad u poimanju deteta te $\mathrm{u}$ formiranju kvalitetnog odnosa odrastao - dete. S jedne strane, govori se o „konzumerističkom djetinjstvu“ (Bauman) koje gradi novi vek i prisutnosti fenomena "rastućeg haosa" (Bronfenbrenner, 1997) u okviru užeg i šireg društvenog konteksta, u kojem i dalje dominiraju "poslušništvo, pasivnost, hijerarhuja, takmičenje i dominacija odraslog nad detetom" (Zornado, 2001: 219), tradicionalni pristup kontrolisanja dečjeg funkcionisanja koji rezultira od ranog detinjstva učenjem oštre razlike "ja" i "drugi" po principu "odnosa moći” (Zornado, 2001: 219).

Sa druge strane, prisutna je borba za "oslobođenje detinjstva", kako navodi Hengst (2001), kao i razvijanje "kulture pregovaranja" (Vandenbroeck i Bouverne-De Bie, 2006: 133). To upućuje na razvijanje nove perspektive deteta koja se oslanja na liberalizam i "responsabilizaciju" kao strategiju koja daje individui odgovornost da u skladu sa svojim kapacitetima upravlja sobom (Smith, 2011: 25). Ovaj nesklad poziva na adekvatno pedagoško delovanje koje se ne temelji na odnosu moći već na strategijama "scaffolding"-a, u kojem su otvorene mogućnosti obostranog rasta i razvoja, dakle, i deteta/učenika i nastavnika kroz puteve dečjeg saznavanja i internalizovanja višedimenzionalne i promenljive stvarnosti novog veka.

U cilju promene ovih protivrečnosti koje su zastupljene u pedagoškoj praksi i na našim prostorima, poželjno je razmotriti pitanje potrebe institucionalizacije "scaffolding"-a kao strateškog pedagoškog pristupa kako bi se mogla realizovati kvalitetna empirijska provera njegove efikasnosti $\mathrm{u}$ vaspitno-obrazovnom procesu.

Polazeći od razmatranih teorijskih i empirijskih podataka do kojih su došli mnogi teoretičari i praktičari, sumiramo pozitivne efekte "scaffolding"a u različitim domenima celokupnog psiho-fizičkog razvoja deteta: 
- kognitivni domen - "scaffolding" poziva na proces identifikovanja “ZPD” u cilju stimulacije kognitivnih procesa, na učenje u problemskim situacijama, koje rezultira usvajanjem znanja na nivou razumevanja, povezivanjem veza i odnosa nastavnih i drugih sadržaja putem kojih učenik konstruiše svoje znanje i dostiže nivo metakognitivnog funkcionisanja, što pospešuje samoregulaciju;

- socijalni domen - "scaffolding" se temelji na interakciji, intersubjektivnosti i ko-konstrukciji znanja na relaciji nastavnik učenik, učenik - učenik; u tom kontekstu pospešuje razvoj socijalizacije, prihvatanje mišljenja drugog, razmenu mišljenja, razumevanje i usvajanje osnovnih društvenih normi koje određena društvena zajednica preferira, jer je konstantno prisutan međusobni fokus individua jednih na druge;

- emocionalni domen - "scaffolding" pristup pomaže učeniku da razvije osećaj empatije, stekne uvid u značenje vlastitih emocionalnih doživljaja i spozna njihovu vrednost; motivacija i volja su osnovni pokretači u procesu učenja, a njihov izvor je u specifičnostima emocionalnog stanja individue; svaka interakcija zasnovana na emocionalnoj podršci rezultira razvojem pozitivne samopercepcije, kao i razvoju samoprihvatanja, samopoštovanja i samopouzdanja;

- domen jezika - u "scaffolding"-u govor je glavno oruđe interakcije koja se bazira na međusobnoj komunikaciji, slobodi izražavanja i stimulativnoj podršci nastavnika verbalnim vođenjem kroz obrazovni proces; to ujedno efikasno pospešuje obogaćivanje vokabulara učenika i razvijanje komunikacionih veština kao važne kompetencije novog veka;

- fizički domen - "scaffolding" proširuje perspektivu individue u odnosu na vlastite mogućnosti i pospešuje ovladavanje vlastitim telom, razvojem koordinacije i organizacije pokreta $u$ raznovrsnim aktivnostima, što direktno utiče na razvoj samokontrole $u$ finim $i$ krupnim motoričkim radnjama.

Sagledavanjem fundamentalnih karakteristika "scaffolding"-a, možemo zaključiti da one nisu kulturno- istorijski niti društveno-ekonomski uslovljene. Njegov značaj ogleda se u efikasnosti procesa učenja i 
podučavanja, holističkom pristupu detetu/učeniku koji maksimalizuje njegove potencijale, proširuje pogled na svet i priprema za adekvatno funkcionisanje u fluidnom vremenu u kojem živimo. Zbog toga, apelujemo na potrebu za ozbiljnijem teorijskom i empirijskom proučavanju koncepta na našim prostorima kako bi došli do relavantnih činjenica i diseminirali ih $\mathrm{u}$ cilju kvalitetnijeg i efikasnijeg integrisanja u pedagošku praksu. U ovom kontekstu, postavljamo pitanje potrebe adekvatnog prevoda termina "scaffolding" - u cilju boljeg i lakšeg poimanja i upotrebe u pedagoškoj teoriji i praksi.

\title{
CONSIDERING THE POSSIBILITY TO APPLY "SCAFFOLDING" IN THE CONTEMPORARY EDUCATIONAL PROCESS
}

\begin{abstract}
"Scaffolding" is a contemporary pedagogical approach introduced by Wood et al. (1976) in their attempt to establish the most important components of teaching, based on pedagogical views of L.S. Vygotsky. Changes in the Modern Age affect the demographic profile of early childhood, which changes rapidly in the classroom, and therefore it is necessary to change our theories, ideas, and educational practice as well. A biggest debate in the field of early childhood is to define a role of an oriented teacher in the approach which places a child in the center of the educational process. Considering the essence of "scaffolding", which is based on interaction, co-construction, inter-subjectivity, and a significance of the role of an adult in maximizing the child's potentials, and the development of meta-cognition in different aspects of development (cognitive, social, emotional, physical and the language domain), we emphasize its pedagogical value and valency. Numerous contradictions of the postmodern conception of childhood point to the need for the pedagogical approach based on the wide range of intersubjectivity, which exactly implies the application of "scaffolding". By analyzing the available scientific-research material, we complete the most frequent concept of "scaffolding" in the literature, as a process in which a child has provided challenging tasks and activities in a supportive environment, which stimulate his/her ability to independently solve the problem. Accordingly, we raise the question of the possibility to integrate "scaffolding" in our educational practice, and the possibility to appropriately translate the term in Serbian language in order to facilitate its acceptance, comprehension, and the use both in educational theory and practice.
\end{abstract}

KEY WORDS: scaffolding; interactions; pupil; teacher; teaching. 


\section{REFERENCE}

Anning, A. (2004). The nature of knowledge in early years. U: A. Anning, J. Cullen i M. Fleer (Ur.), Early Childhood Education Society and Culture (pp. 57-95). London: Sage.

Blanton, W.E., Menendez, R., Moorman, B.G. i Pacifici, C.L. (2013). Learning to Comprehend Written Directions through Participation in a Mixed Activity Sistem. Early Education and Development (14), br.3, 317-318.

Bingham, S., Grau, V., Pasternak, P.D., Sangster, C. i Whitebread, D. (2007). Development of Metacognition and Self-Regulated Learning in Young Children: Role of Collaborative and Peer-Assisted Learning. Journal of Cognitive Education and Psychology (6), br.3, 438-447.

Berk, E.L. i Winsler, A. (1995). Vygotsky`s Approach to Development: The Social Origins of Individual Mental Functioning. U: C. Copple, D. Hudson i J. Zibulsky (Ur.), Scaffolding Children`s Learning: Vigotsky and Early Childhood Education (pp. 11-50), Washington: NAEYC.

Berk, E.L. i Winsler, A. (1995). Vygotsky`s Theory in Early Childhood Classrooms. U: C. Copple, D. Hudson i J.Zibulsky (Ur.), Scaffolding Children's Learning: Vigotsky and Early Childhood Education (pp. 113-148), Washington: NAEYC.

Bronfrebrener, J. (1997). Ekologija ljudskog razvoja, Beograd: Zavod za udžbenike i nastavna sredstva.

Duncan, M.R., i Tarulli, D. (2010). Play as the Leading Activity of the Preshool Period: Insights from Vigotsky, Leontev, and Bakhtin. Early Education and Development (14), br.3, 278-279.

Evans, M.A., Moretti, S., i Fox, M. (2010). Parent Scaffolding in Children`s Oral Reading. Early Education and Development (14), br.3, 366.

Fleer, M., i Richardson, C. (2004). Mapping the transformation of understanding. U: A. Anning, J. Cullen i M. Fleer (Ur.), Early Childhood Education - Society and Culture (pp. 119-136). London: Sage.

Freire, P. (1996). Pedagogy of Opressed, London. 
Helm, H.J. (2015). Supporting the Development of the Mind Through Deep Project Work. U: S. Ryan (Ur.), Becoming Young Thinkers (pp. 2241). New York: NAEYC.

Habermas, J. (1979). Communication and the Evolution of Society, Boston: Beacon Press.

Habermas, J. (1987). The theory of communicative action. Lifeworld and Sistem: A critique of Functionalist Reson (2), Boston: Beacon Press.

Habermas, J. (1996). Some Further Clarifications of the Concept of Communicative Rationality. U: M. Cooke (Ur.), On the pragmatic of Communication (pp. 307-343), Cambridge (1998): MIT Press.

Jordan, B. (2004). Scaffolding learning and co-constructing understanding. U: A. Anning, J. Cullen i M. Fleer (Ur.), Early Childhood Education - Society and Culture (pp. 31-42). London: Sage.

Kuyk, J.J. (2011). Scaffolding - how to increase development? European Early Childhood Education Research Journal (19), br.1, 137-139.

Marjanović, A. (2013). Ideje Aleksandre Marjanović o nauci i obrazovanju predškolskog deteta. Krugovi detinjstva, br.2, 85.

Crowley, K., Miles, G., Mclnnes, K. i Howard, J. (2013). The nature of adult - child interaction in the early years classroom: Implications for children`s perceptions of play and subsequent learning behavior. European Early Childhood Education Research Journal (21), br.2, 271-278.

Miljak, A. (2009). Življenje dece u vrtiću, Zagreb: SM Naklada.

Pijaže, Ž. i Inhelder, B. (1983). Intelektualni razvoj deteta, Beograd: Zavod za udžbenike i nastavna sredstva.

Pijaže, Ž. (1983). Poreklo saznanja, Beograd: Nolit.

Pesco, D. i Gagne, A. (2015). Scaffolding Narrative Skills: A Meta Analysis of Instruction in Early Childhood Settings. Early Education and Development (14), br.3, 14.

Rogoff, B. (2001). How Is This a Community? U: B. Rogoff, C.G. Turkanis i L. Bartlett (Ur.), Learning together Children and Adults in a School Community (pp. 61-91). New York: Oxford.

Rogoff, B. (1990). The Individual and the Sociocultural Context. Apprenticeship in Thinking (pp. 25-65). New York: Oxford. 
Redford, Dž. i Kirbi, R. (1979). Ličnost u psihologiji, Beograd: Nolit.

Scrimsher, S. i Tudge, J. (2010). The Teaching/Learning Relationship in the First Years of School: Some Revlutionary Implications of Vigotsky`s Theory. Early Education and Development (14), br.3, 298-306.

Slunjski, E. (2009). Postizanje odgojno - obrazovne prakse vrtića uskladjene sa prirodom djeteta i odraslog. Život i škola, br.22, 107-111.

Slunjski, E. (2012). Tragovima dečjih stopa: istraživačka perspektiva djeteta u radu na projektu. Zagreb: Profil international (monografija).

Smith, K. (2011). Producing governable subjects: Images of Childhood old and new. Childhood (pp. 24-37).

Tarner, Dž. (1979). Saznajni razvoj, Beograd: Nolit.

Vigotski, S.L. (1996). Naučno nasledje, Beograd: Zavod za udžbenike i nastavna sredstva.

Vigotski, S.L. (1996). Dečja psihologija, Beograd: Zavod za udžbenike i nastavna sredstva.

Vigotski, S.L. (1996). Problemi opšte psihologije, Beograd: Zavod za udžbenike nastavna sredstva.

Vigotski, S.L. (1977). Mišljenje i govor, Beograd: Zavod za udžbenike i nastavna sredstva.

Vandenbroeck, M. i Bouverne - De Bie, M. (2006). Children`s Agensy and Educational Norms: A Tensed Negotiation, Childhood, 127-143.

Winsler, A. (2010). Introduction to special issue: Vigotskian Perspectives in Early Childhood Education: Translating Ideas into Classroom Practice. Early Education and Development (14), br.2, 254-257.

Wyness, M. (2013). Children`s participation and intergenerational dialouge: Bringing adults back into analysis. Childhood (20), br.4, 429-442.

Yudina, E. (2010). The Teacher's Position in Adult - Child Interaction in Relation to a Child`s Zone of Proximal Development. U: A. Tuna i J. Hayden (Ur.), Early Childhood Programs as the Doorway to Social Cohesion: Application of Vigotsky's Ideas from an East - West Perspetive (pp. 45-62). Cambridge Schoolars Publishing.

Zornado, J. (2001): Inventing the child, Culture, Ideology and the Story of Childhood. New york: Garland Publishing. 